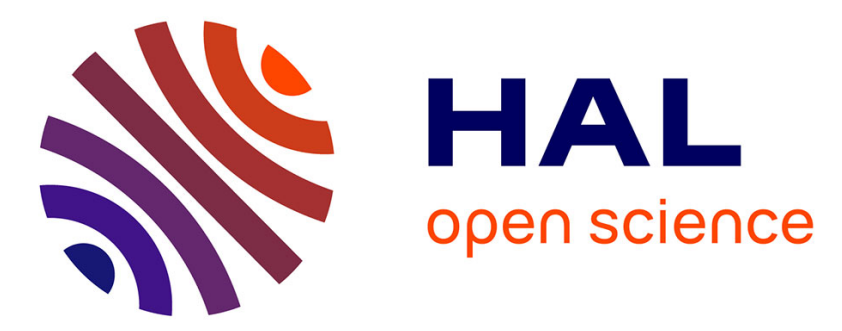

\title{
Comparison of Two Bone-Preparation Methods for Radiocarbon Dating: Modified Longin and Ninhydrin
}

J-P Dumoulin, C Messager, H Valladas, L Beck, I Caffy, E Delqué-Količ, C Moreau, M Lebon

\section{- To cite this version:}

J-P Dumoulin, C Messager, H Valladas, L Beck, I Caffy, et al.. Comparison of Two Bone-Preparation Methods for Radiocarbon Dating: Modified Longin and Ninhydrin. Radiocarbon, 2017, 59 (6), pp.1835-1844. 10.1017/RDC.2017.132 . hal-03225880

\section{HAL Id: hal-03225880 \\ https://hal.science/hal-03225880}

Submitted on 18 Jun 2021

HAL is a multi-disciplinary open access archive for the deposit and dissemination of scientific research documents, whether they are published or not. The documents may come from teaching and research institutions in France or abroad, or from public or private research centers.
L'archive ouverte pluridisciplinaire HAL, est destinée au dépôt et à la diffusion de documents scientifiques de niveau recherche, publiés ou non, émanant des établissements d'enseignement et de recherche français ou étrangers, des laboratoires publics ou privés. 
COMPARISON OF TWO BONE-PREPARATION METHODS FOR RADIOCARBON DATING: MODIFIED LONGIN AND NINHYDRIN

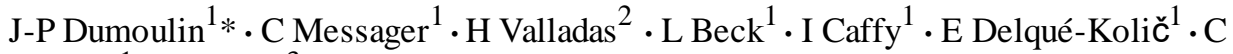 \\ Moreau ${ }^{1} \cdot$ M Lebon $^{3}$ \\ ${ }^{1}$ Laboratoire de Mesure du Carbone 14 (LMC14), LSCE/IPSL, CEA-CNRS-UVSQ, Université Paris-Saclay, F- \\ 91191 Gif-sur-Yvette, France. \\ ${ }^{2}$ Laboratoire des Sciences du Climat et de l'Environnement, LSCE/IPSL, CEA-CNRS-UVSQ, Université Paris-Saclay, F- \\ 91198 Gif-sur-Yvette, France. \\ ${ }^{3}$ UMR 7194 - Histoire Naturelle de l'Homme Préhistorique. Département de Préhistoire du CNRS, MNHN, \\ UPVD, SU, Musée de l'Homme, 17 Place du Trocadéro, 75116 Paris, France.
}

\begin{abstract}
In this paper, first results comparing modified Longin and ninhydrin collagen extraction methodologies are presented. The goal of this study is to investigate the bones of several species with different ages, preservation condi-tions, and collagen contents to determine the most suitable preparation method. Different types of samples are used such as VIRI samples, previously dated bones, and background samples. Each bone has undergone elemental analysis, infrared analysis, and ${ }^{14} \mathrm{C}$ measurement. The results are presented and the advantages and disadvantages of each preparation method are discussed. In general, results obtained by the two methods are in accordance with the consensus value for $2 \sigma$ uncertainty. For VIRI I and a mammoth bone, the ninhydrin preparation gives, respectively, $8450 \pm 70 \mathrm{BP}$ and 14,870 $\pm 60 \mathrm{BP}$ whereas the modified Longin process gives $8365 \pm 45 \mathrm{BP}$ and 14,750 $\pm 100 \mathrm{BP}$ in agreement with the expected values. From the experimental point of view, the modified Longin process is easier to implement than the ninhydrin protocol. From this approach, we can conclude that the modified Longin process could be preferred in most cases and particularly when the amount of bone is small and the sample is not too contaminated.
\end{abstract}

KEYWORDS: bone samples, collagen, Longin, ninhydrin, radiocarbon AMS dating.

\title{
INTRODUCTION
}

The Laboratoire de Mesure du Carbone 14 (LMC14) and its Pelletron tandem AMS unit ARTEMIS are dedicated to radiocarbon $\left({ }^{14} \mathrm{C}\right)$ measurements for the research programs of five French institutions. About 4500 samples, comprising unknown samples, standards and blanks, are measured every year, including more than 200 samples dedicated to specific LMC14 research programs. Over many years, we have improved our protocols in order to extend our range of dated samples. Various types of materials are prepared and measured, such as organic matter, carbonate (Dumoulin et al. 2017), dissolved inorganic carbon in water (Dumoulin et al. 2013), and archaeological iron alloys (Leroy et al. 2015).

Recently, we have investigated the preparation of bone samples. Existing protocols to extract the collagen include modified Longin (Longin 1971; Brown et al. 1988), ultrafiltration (Bronk Ramsey et al. 2004; Brock et al. 2007), single amino acid/hydroxyproline extraction (Marom et al. 2013) and ninhydrin (Nelson 1991; Tisnérat-Laborde et al. 2003). In this study, we have selected two methods: the ninhydrin and a modified Longin protocols.

The aim of this paper is to compare the efficiency of these two collagen-extraction processes according to the bone age, the preservation condition, and the collagen content. For this study, bones of known ages including three mammal specimens of the Fifth International Radiocarbon Intercomparison and ${ }^{14} \mathrm{C}$-free background samples have been used. Bone preservation has been characterized by elemental analysis and Fourier transform infrared spectrometry in attenuated total reflection mode (ATR-FTIR). Elemental analysis directly provides concentrations of carbon and nitrogen while the second technique quantifies the collagen content (Lebon et al. 2016).

\footnotetext{
*Corresponding author. Email: dumoulin@1sce.ipsl.fr.
} 
The ${ }^{14} \mathrm{C}$ results of the bones prepared with the two processes-modified Longin and ninhydrin techniques-are presented and the best protocol to be applied according to the different types of bone samples is discussed.

\section{MATERIAL AND METHODS}

\section{Bone Samples}

A bone is a porous network of mineralized fibers, made up of 20-30\% by weight of organic matter (collagen), and $60-70 \%$ by weight of mineral matter (hydroxyapatite). Water ( $10 \%$ by weight) and other chemical elements in very small quantities, such as sulfur, are also present. It is possible to visually distinguish two different porosities in a bone: the cortical bone is compact whereas the trabecular bone is very porous (Figure 1). For ${ }^{14} \mathrm{C}$ dating of archaeological samples, the compact cortical bone is chosen and the trabecular bone is removed. This porous part is more altered by diagenesis and can trap a lot of contaminants (Dauphin et al. 2015). However, Ubelaker and Parra (2011) found that for modern bone, the trabecular tissue actually gave better dates than the cortical. However, this is only due to faster turnover of collagen in the trabecular material.

In this study, different bone samples have been chosen because of their species (mammoth, horse, whale) and ages (Table 1). Three VIRI samples E, F, and I (Scott et al. 2010) and different samples with known ages have been selected. They originate from different archeological sites and are sufficiently varied to offer the possibility to see which preparation method is the most suitable according to the bone characteristics. The Scladina bone specimens come from layer $4 \mathrm{~b}$, which is older than 120,000 years according to thermoluminescence dating (Debenham 1998).

\section{COLLAGEN-PRESERVATION STUDY}

To determine if a bone can be dated, the preservation condition of the collagen has to be estimated. Several researchers (Gillespie et al. 1984; DeNiro 1985; Ambrose et al. 1990; van Klinken 1999; Bocherens et al. 2005; Beck et al. 2012) have demonstrated that the percent of nitrogen $(\% \mathrm{~N})$ for whole bone can be a useful prescreening technique to identify bones suitable for ${ }^{14} \mathrm{C}$ dating. According to Brock et al. (2010), the acceptable limit to prepare a bone sample is $\% \mathrm{~N}>0.7-0.8 \%$. Below this value, the collagen is not well-preserved enough for dating.

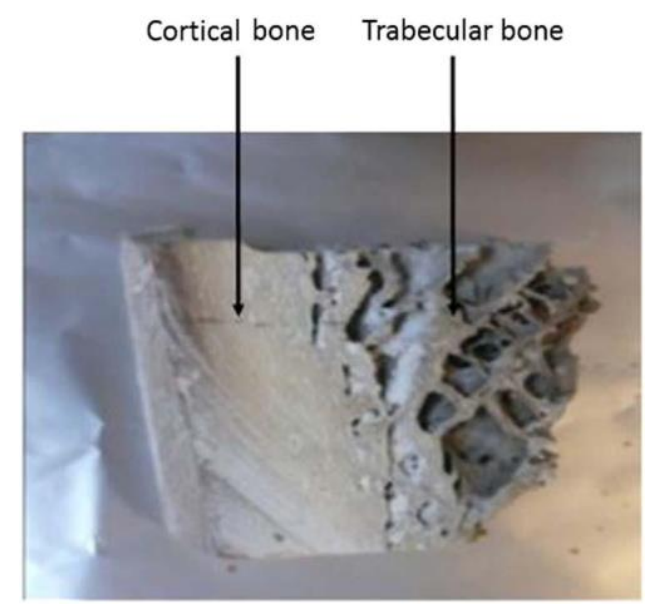

Figure 1 Sample showing the compact cortical bone and the spongy trabecular bone. 
Table 1 Bone samples selected for this study.

\begin{tabular}{llc}
\hline Sample/species & Geographic origin/site & Expected age (BP) \\
\hline Buzha 02/mammoth & Ukraine/Buzankaya rock shelter & $14,610 \pm 80^{*}$ \\
BK3-08-05/horse & Crimea/Buran-kaya & $34,050 \pm 240^{* *}$ \\
Aliquot 10/mammoth & England (Wiltshire)/Thames sediment & $>147,000 \pm 20,000^{* * *}$ \\
VIRI E/mammoth & USA (Dawson City, Yukon)/Quartz Creek, & $39,305 \pm 121$ \\
VIRI F/horse & Russia (Siberia)/Scythian burial site & $2513 \pm 5$ \\
VIRI I/whale & Norway/Svalbard archipelago & $8331 \pm 6$ \\
Sclayn/mammal & Belgium (Andenne)/Scladina Cave, layer 4 & Older than 120,000 yr \\
Sc91/mammal & Belgium (Andenne)/Scladina Cave, layer 4 & Older than 120,000 yr \\
\hline
\end{tabular}

*Expected age is an average value of two previous results measured at LSCE and Groningen laboratories.

**GrA-40485.***Lewis et al. (2006).

The exogenous contamination rate $\left(\% \mathrm{C}_{\text {excess }}\right)$ can be determined in a bone by comparing the measured percent carbon $(\% \mathrm{C})$ with the theoretical \%C. According to Person et al. (1996) and Bocherens et al. (2005), the following equations were defined:

$$
\% C_{\text {theory }}=2: 7^{\prime} \% \mathrm{~N}+1: 4 \mathrm{so} \text {; by extension } \% \mathrm{C}_{\text {excess }}=\% \mathrm{C}_{\text {measured }} \% \mathrm{C}_{\text {theory }}
$$

The classic method for measuring the concentrations of $\mathrm{C}$ and $\mathrm{N}$ is based on a carbon and nitrogen elemental analyzer. We uses a Thermo Fisher Scientific Flash 2000 series.

The detection and quantification of the collagen content have been also measured by ATR-FTIR with a Vertex 70 spectrometer (Bruker) equipped with a ATR-GoldenGate accessory (Specac). The relative collagen content of the bone samples is calculated by measuring the area ratio of the amide I and phosphate peaks of the IR spectrum. The amide I and the phosphate band areas are measured between 1710 and $1590 \mathrm{~cm}^{-1}$ and between 1110 and $940 \mathrm{~cm}^{-1}$, respectively, according to the methodology developed by Lebon et al. (2016). The limit of detection of this method is 0.5 $\mathrm{wt} \%$ for $\mathrm{N}$ (corresponding to $\sim 3 \mathrm{wt} \%$ of collagen) and the limit of quantification is $0.7 \pm 0.2 \mathrm{wt} \%$ $(\sim 4 \pm 1.2 \mathrm{wt} \%$ of collagen).

Elemental analysis and ATR-FTIR are carried out on the same samples for both methods of preparation. In addition, the ATR-FTIR method is applied to the different steps of the collagen extraction by analyzing the bone powder, the residue collected on the glass filter, and the extracted collagen.

\section{COLLAGEN EXTRACTION}

A mass of 1 or $2 \mathrm{~g}$ is cut with a small electrical saw from the cortical part of each bone (compact porosity). The trabecular bone (spongy porosity) is removed. Mechanical cleaning of the bone surface is carried out by sand blasting ( $27 \mu \mathrm{m}$ diameter aluminum oxide) to remove macrocontaminants such as sediment. An aliquot of a few milligrams of bone is first drilled out to evaluate the bone preservation by elemental analysis and ATR-FTIR spectrometry. The rest of the sample is used for the collagen extraction. Two processes of collagen extraction-the modified Longin and the nynhidrin methods-are tested and compared.

The modified Longin method, used in many laboratories, is described in Figure 2. The bone powder is treated at room temperature with $1 \mathrm{M} \mathrm{HCl}$ to remove carbonates, phosphates, and fulvic acids. The duration depends on the sample weight and its carbonates content. The acid solution in changed several times until the $\mathrm{pH}$ of the solution remains $\operatorname{acid}(\mathrm{pH}=1)$. 


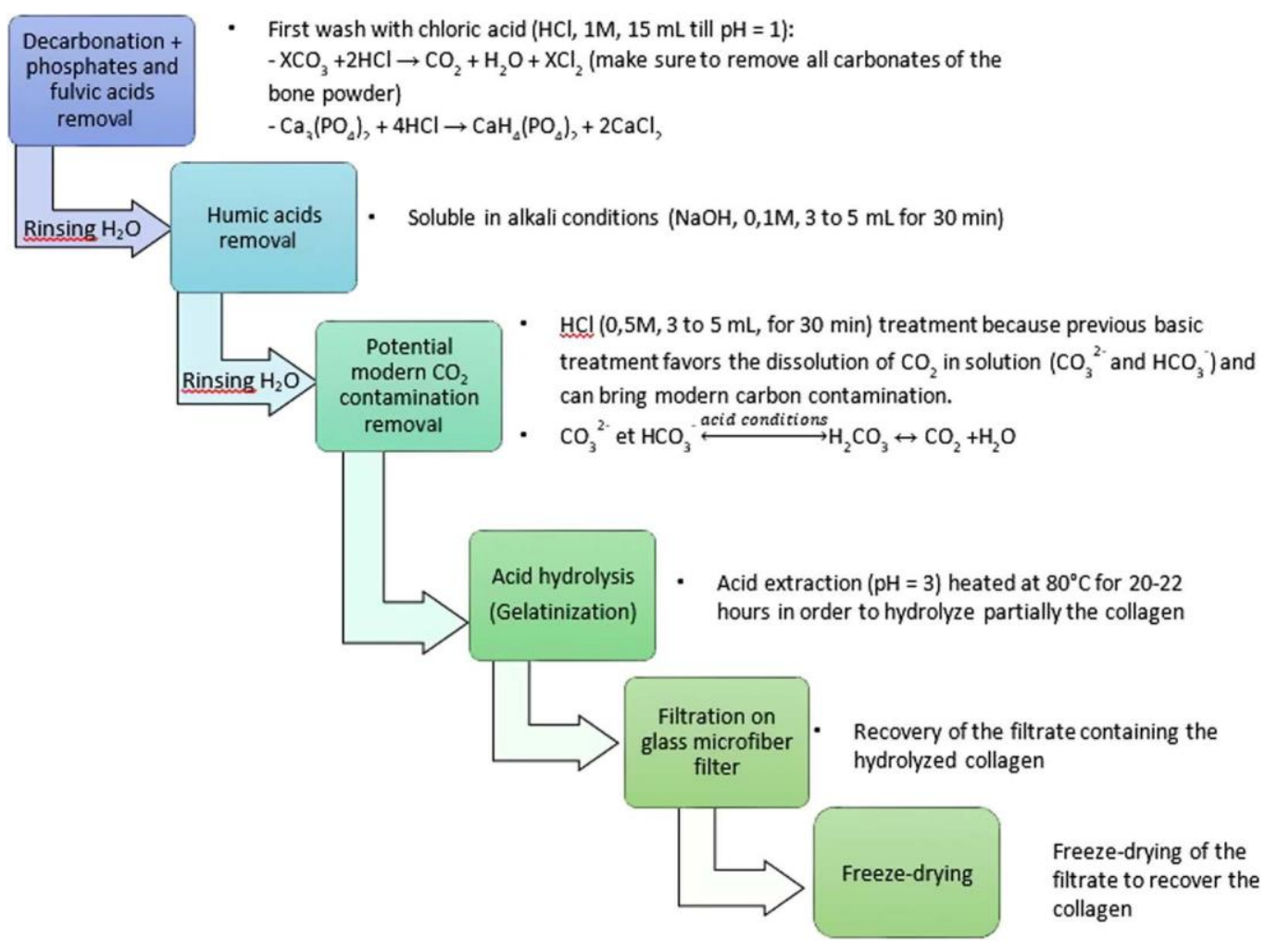

Figure 2 Detailed steps of the modified Longin method.

Then, after three washes with deionized water, the humic acids are removed in a $0.1 \mathrm{M} \mathrm{NaOH}$ alkali solution for $30 \mathrm{~min}$. After three more water washes, a last $0.5 \mathrm{M} \mathrm{HCl}$ treatment is applied. The collagen residue is finally washed with deionized water until a neutral $\mathrm{pH}$ is reached. After the $\mathrm{ABA}$ (acid-base-acid) pretreatment, the collagen is gelatinized in a $\mathrm{pH} 3$ solution at $80^{\circ} \mathrm{C}$ for 20-22 $\mathrm{hr}$ and then filtrated on a clean glass microfiber filter (GE-Whatman, $0.7 \mu \mathrm{m}$ ). The collected gelatin is freeze dried. Then, $2-3 \mathrm{mg}$ of pure collagen is placed in a quartz tube with an excess of $\mathrm{CuO}(300-400 \mathrm{mg})$ and a $1-\mathrm{cm} \mathrm{Ag}$ wire. The quartz tube is then sealed under vacuum $\left(5.10^{-6}\right.$ mbar) and heated at $850^{\circ} \mathrm{C}$ for $5 \mathrm{hr}$ in an external oven. The $\mathrm{CO}_{2}$ gas is separated from $\mathrm{H}_{2} \mathrm{O}$ on a vacuum line using a dry ice/alcohol trap $\left(-78^{\circ} \mathrm{C}\right)$. The sample is then cryogenically collected with liquid nitrogen $\left(-196^{\circ} \mathrm{C}\right)$ into vials to be transferred to the graphitization lines (Vogel et al. 1984; Dumoulin et al. 2017).

The ninhydrin method is described in Figure 3 . In this method, a ninhydrin solution ( $50 \mathrm{mg}$ of ninhydrin in $2 \mathrm{~mL}$ of sodium citrate) is first added to the sample for $10 \mathrm{~min}$ at $100^{\circ} \mathrm{C}$ after a first acid pretreatment $(1 \mathrm{M} \mathrm{HCl}$ at room temperature). This first ninhydrin step reacts only with the free amino acids weakly bound to the collagen and suspected as being a contaminant (TisnératLaborde et al. 2003). After this step, the solution has a pink color and the collagen has to be rinsed with deionized water until the solution is clear and no color remains.

The collagen residue is then hydrolyzed with $2 \mathrm{ml} 6 \mathrm{M} \mathrm{HCl}$ solution at $100^{\circ} \mathrm{C}$ overnight to break the collagen molecules into free amino-acid molecules. The solution is filtrated on a clean glass 


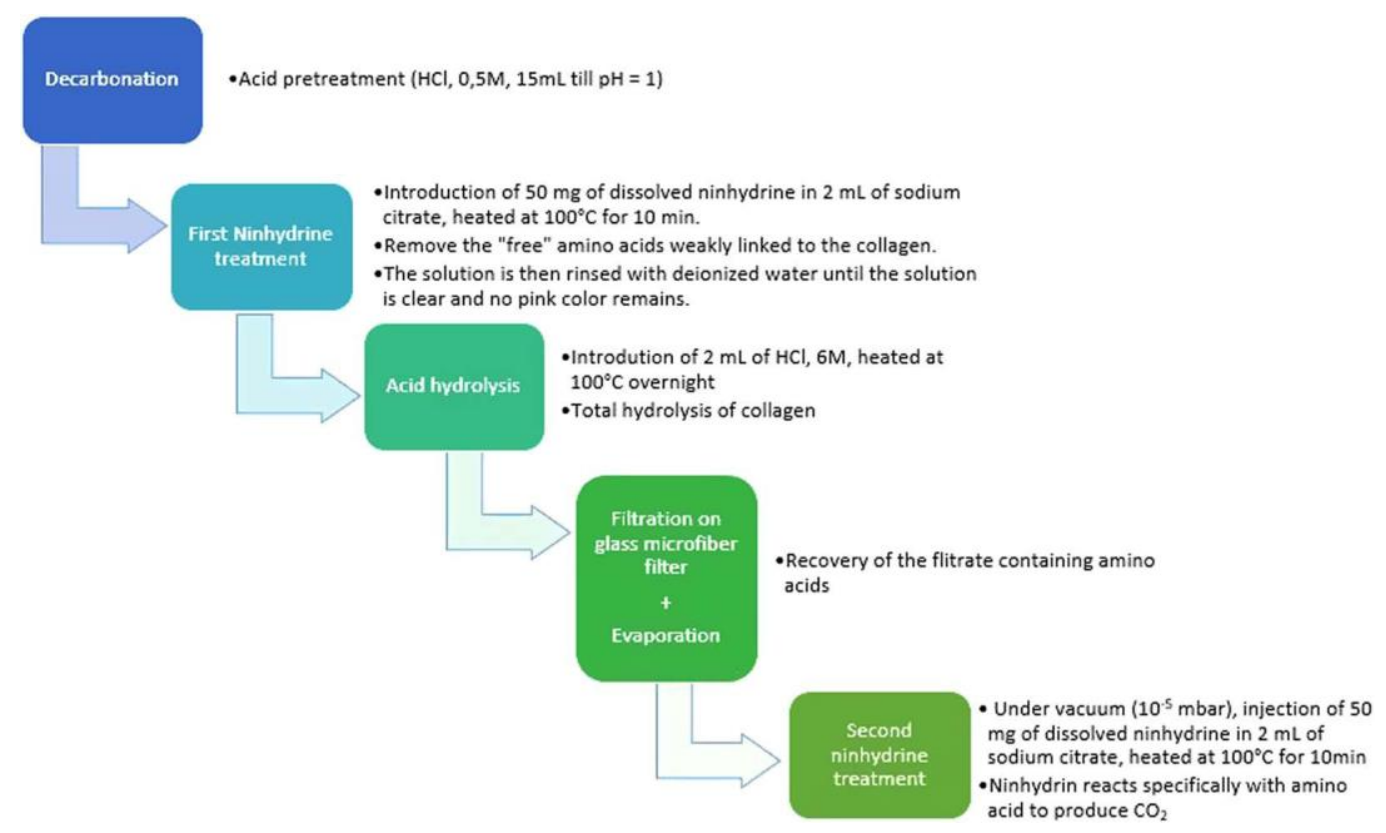

Figure 3 Detailed steps of the ninhydrin method.

microfiber filter (GE-Whatman- $0.7 \mu \mathrm{m}$ ), then rinsed and evaporated under nitrogen three times to remove as much acid as possible.

The filtrate containing free amino acids from the collagen is placed in a special glass setup under vacuum until $10^{-5} \mathrm{mb}$ and before proceeding to the $\mathrm{CO}_{2}$ extraction. A second solution of $50 \mathrm{mg}$ of ninhydrin dissolved in $2 \mathrm{~mL}$ of sodium citrate is introduced with a syringe through a septum and heated at $100^{\circ} \mathrm{C}$ (Figure $4 \mathrm{a}$ ). The reaction is quite exothermic and the boiling has to be controlled with the valve above. The produced $\mathrm{CO}_{2}$ passes through two successive "water traps" (dry ice and ethanol at $-78^{\circ} \mathrm{C}$ ) to remove the water and is collected with a liquid nitrogen trap at $196^{\circ} \mathrm{C}$ in vials (Figure 4b) before the graphitization step (Vogel et al. 1984; Dumoulin et al. 2017).

After preparation of the collagen, combustion, purification, and graphitization, the samples are measured by the ARTEMIS accelerator mass spectrometer (Moreau et al. 2013).

\section{RESULTS AND DISCUSSION}

\section{Collagen-Preservation Test}

The results concerning the preservation of the bones are presented in Table 2. Elemental analysis directly measures $\% \mathrm{~N}$ and $\% \mathrm{C}$ values. $\% \mathrm{C}_{\text {theory }}$ and the $\% \mathrm{C}_{\text {excess }}$ are calculated according to the above equations. We observe that the VIRI samples and Buzha 02 are well preserved with a nitrogen content around 3\% indicating that a suitable quantity of collagen remains in the sample (around 20\%). The nitrogen content of BK3-08-05 and Sc91 is around 0.7\% showing that the collagen is degraded, close to the acceptable limit for a ${ }^{14} \mathrm{C}$ measurement. In all cases, the samples are not highly contaminated because the contamination rates $\left(\% \mathrm{C}_{\text {excess }}\right)$ are between 1 and $2 \%$, lower than the maximum accepted value of 5-10\%. 
(a)

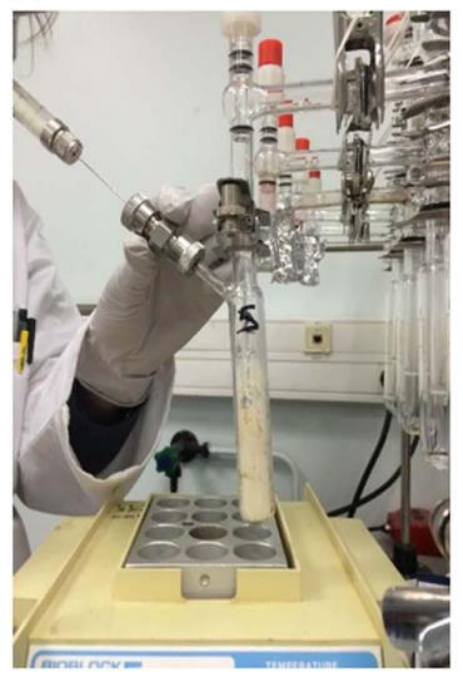

(b)

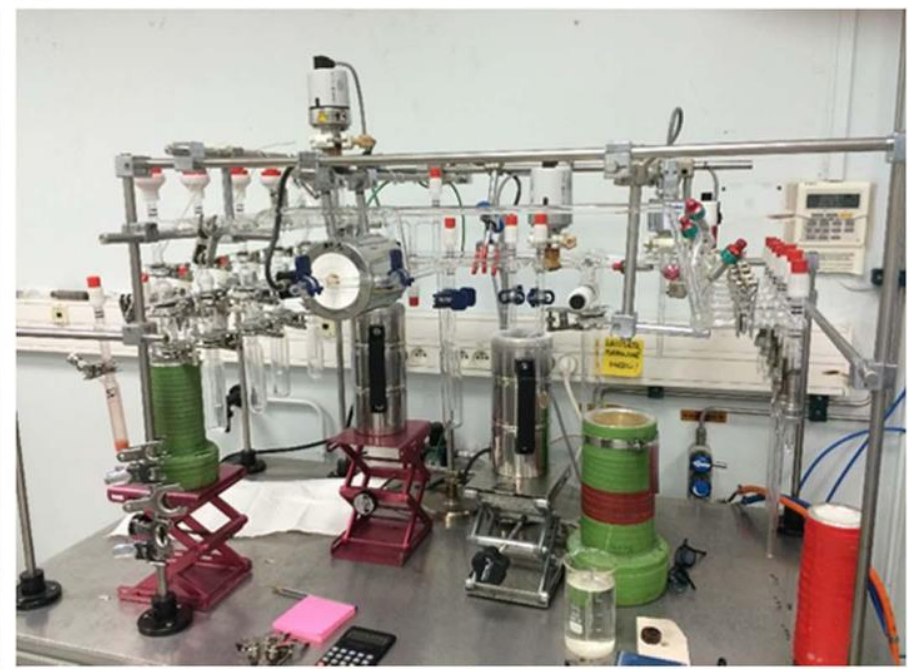

Figure 4 (a) First ninhydrin introduction through the septum and (b) $\mathrm{CO}_{2}$ collection line.

The ATR-FTIR analysis provides the $\% \mathrm{~N}$ and the collagen content calculated from the amide I: phosphate peak ratio of the IR spectrum (Figure 5). The results of the ATR-FTIR and elemental analyses are close to each other in most of the cases. The IR method estimates directly the quantity of collagen remaining in the bone and the elemental analysis gives the $\% \mathrm{C}_{\text {excess }}$ corresponding to the contaminant to be removed.

The ATR-FTIR analysis also provides information on the different steps of the pretreatment (Figure 5). In the non-pretreated bone powder, the presence of carbonates, phosphates as well as amide I and II (from the collagen) are observed. The residue on the filter contains traces of collagen that has not been extracted by the hydrolysis step (gelatinization) and the insoluble phosphates. In the extracted collagen, the carbonates and phosphates peaks are very weak and the amide I and II peaks are well defined. These results show that the major part of the non-collagen components are removed by the chemical pretreatment.

\section{${ }^{14} \mathrm{C}$ RESULTS AND DISCUSSION}

The results are presented in Table 3. For both methods, samples expected as background samples (Aliquot 10, Sclayn, and Sc91) do not have any background correction. All other samples get a background correction. The modified Longin results are obtained by subtracting the Aliquot 10 value $(0.336 \pm 0.014 \mathrm{pMC})$ and the ninhydrin results are obtained by subtracting the Sclayn value $(0.582 \pm 0.026 \mathrm{pMC})$.

When using the Longin method, the results are very close to the expected values. All the VIRI sample results are in accordance with the consensus values. In addition, the value obtained for Aliquot 10 is in the age range for an old sample. Only one sample, Sclayn, appears too young for a background sample. This is probably because some contaminants remain in the collagen before combustion. For this sample, the result obtained by the ninhydrin method is better.

With the ninhydrin method, the results for VIRI E and VIRI I samples are in accordance with the consensus values. Unfortunately, not enough $\mathrm{CO}_{2}$ was collected after the second ninydrin 
Table 2 Comparison of elemental analysis and ATR-FTIR analysis for the different bone samples. Two sub-samples, labelled and were analyzed to check the homogeneity of the collagen preservation.

\begin{tabular}{|c|c|c|c|c|c|c|c|c|}
\hline \multirow[b]{2}{*}{ Reference } & \multirow[b]{2}{*}{ Species } & \multicolumn{5}{|c|}{ Elemental analysis } & \multicolumn{2}{|c|}{ ATR-FTIR analyis } \\
\hline & & $\mathrm{N}$ wt $\%$ & $\begin{array}{l}\text { Mean N } \\
\text { wt\% }(2 \sigma)\end{array}$ & $\begin{array}{l}\text { Mean } C_{\text {measured }} \\
\text { wt\% }(2 \sigma)\end{array}$ & $\begin{array}{l}\mathrm{C}_{\text {theory }} \\
\mathrm{wt} \%\end{array}$ & $\begin{array}{l}\mathrm{C}_{\text {excess }} \\
\mathrm{wt}^{\circ} \%\end{array}$ & $\begin{array}{l}\mathrm{N} w \mathrm{t} \% \\
( \pm 0.2 \mathrm{wt} \%)\end{array}$ & $\begin{array}{l}\text { Collagen wt } \% \\
( \pm 1.2 \mathrm{wt} \%)\end{array}$ \\
\hline Buzha 02 & Mammoth & $\begin{array}{l}3.1 \\
3.4\end{array}$ & $3.2 \pm 0.3$ & $11.2 \pm 0.8$ & 10.1 & 1 & $\begin{array}{l}2.6 \\
3.6\end{array}$ & $\begin{array}{l}14.4 \\
20.0\end{array}$ \\
\hline BK3-08-05 & Horse & $\begin{array}{l}0.6 \\
0.8\end{array}$ & $0.7 \pm 0.2$ & $5 \pm 1$ & 3 & 1 & 0.7 & 4.0 \\
\hline Aliquot 10 & Mammoth & & & & Not ar & & & \\
\hline VIRIE & Mammoth & $\begin{array}{l}3.8 \\
3.5\end{array}$ & $3.6 \pm 0.5$ & $12 \pm 2$ & 11 & 1 & 3.3 & 18.0 \\
\hline VIRI F & Horse & $\begin{array}{l}3.4 \\
3.3\end{array}$ & $3.3 \pm 0.2$ & $11.7 \pm 0.5$ & 10.4 & 1.3 & 3.3 & 17.9 \\
\hline VIRI I & Whale & $\begin{array}{l}2.8 \\
3.7\end{array}$ & $3 \pm 1$ & $12 \pm 4$ & 10 & 2 & $\begin{array}{l}4.1 \\
3.7\end{array}$ & $\begin{array}{l}22.5 \\
20.4\end{array}$ \\
\hline $\begin{array}{l}\text { Sclayn } \\
\text { Sc91 }\end{array}$ & $\begin{array}{l}\text { Mammal } \\
\text { Mammal }\end{array}$ & $\begin{array}{l}0.8 \\
0.6\end{array}$ & $0.7 \pm 0.2$ & $4.1 \pm 0.7$ & $\begin{array}{c}\text { Not ar } \\
3.3\end{array}$ & 0.8 & 1.2 & 6.7 \\
\hline
\end{tabular}




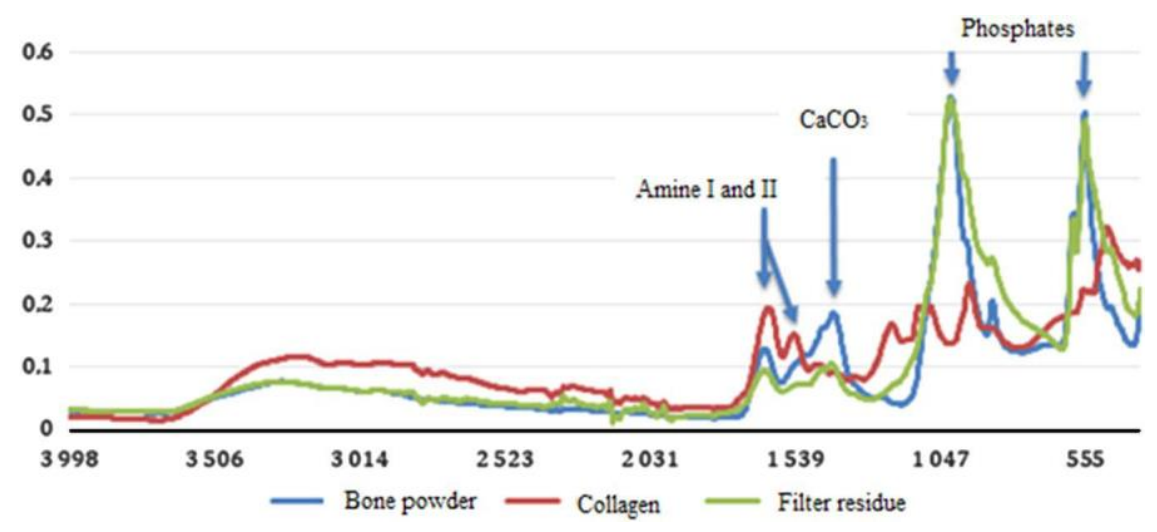

Figure 5 ATR-FTIR spectra of not pretreated bone powder (blue curve), the residue on the glass filter (green curve), and the purified collagen (red curve) after ABA pretreatment of sample Buzha 02. (Colors refer to online version.)

Table $3{ }^{14} \mathrm{C}$ dating results for the two different methods compared to consensus values or previously measured values.

\begin{tabular}{|c|c|c|c|c|c|}
\hline \multirow[b]{2}{*}{ Reference } & \multirow[b]{2}{*}{ Expected age (BP) } & \multicolumn{2}{|c|}{ Modified Longin method } & \multicolumn{2}{|c|}{ Ninhydrin method } \\
\hline & & Target nr & Measured age (BP) & Target nr & Measured age (BP) \\
\hline Buzha 02 & $14,610 \pm 80$ & SacA 45678 & $14,750 \pm 100$ & GifA 80094 & $14870 * \pm 60$ \\
\hline BK3-08-05 & $34,050 \pm 240$ & \multicolumn{4}{|c|}{ Not dated: sample too small and Nwt $\%=0.7$} \\
\hline Aliquot 10 & $147,000 \pm 20,000$ & SacA 45680 & $45,750 \pm 350$ & SacA 45689 & Not enough $\mathrm{CO}_{2}$ \\
\hline VIRI E & $39,305 \pm 121$ & SacA 45682 & $40,000 \pm 1800$ & SacA 45691 & $41,900 \pm 4000$ \\
\hline VIRI F & $2513 \pm 5$ & SacA 45683 & $2570 \pm 30$ & SacA 45692 & Not enough $\mathrm{CO}_{2}$ \\
\hline VIRI I & $8331 \pm 6$ & SacA 45684 & $8365 \pm 45$ & SacA 45693 & $8450 \pm 70$ \\
\hline Sclayn & Older than $120,000 \mathrm{yr}$ & SacA 45685 & $36,560 \pm 500$ & SacA 45695 & $41,340 \pm 360$ \\
\hline Sc91 & Older than $120,000 \mathrm{yr}$ & SacA 45686 & $40,340 \pm 320$ & Average & $42,986 * \pm 2868$ \\
\hline
\end{tabular}

*Previous measurements from LSCE.

step for VIRI F and Aliquot 10. For the old samples Sc91 and Sclayn, the values are superior to $40,000 \mathrm{BP}$ as expected.

Even if the two methods are in accordance each other and in agreement with the consensus values for $2 \sigma$ uncertainty, the ninhydrin results are slightly older than the Longin results. At this stage, it is difficult to determine if the ninhydrin method gives better results for old bones or if the method introduces a bias. It is possible that the improvement in the old age range could be an artifact.

The modified Longin process seems to be applicable for almost all bones and requires only small quantities of bone material. This method is easy to implement and does not require special glassware or setup. Furthermore, it is possible to proceed to several measurements with only one chemical pretreatment. The limit of this method is probably for strongly contaminated bones because some contaminants (such as free amino acids) cannot be fully removed. For that reason, some laboratories add an ultrafiltration step at the end of the protocol (Brown et al. 1988; Bronk Ramsey et al. 2004; Brock et al. 2007; Wood et al. 2010). In this study, we use the ninhydrin method proposed by Nelson (1991). This method appears to be particularly 
recommended for heavily contaminated bones since the first step allows the removal of the free amino acids weakly bound to the collagen. This treatment should have an equivalent effect to the ultrafiltration which removes contaminants under $30 \mathrm{kD}$. The use of the ninhydrin method can be very useful to date certain samples which cannot be accurately cleaned with modified Longin and can be an interesting alternative to the ultrafiltration protocols when consolidants and glues like PVA (polyvinyl acetate) are difficult to remove. We have shown that the collagen extraction by the ninhydrin method is well appropriate for almost all bones. However, we have not tested this method on heavily contaminated bones yet. This interesting aspect of the method will be investigated in a future study. However, the disadvantage of this method is the specific glassware setup necessary to undertake the ninhydrin reaction and the use of this harmful chemical product. Another shortcoming is that the ninhydrin method requires larger quantities of sample (around $1 \mathrm{~g}$ ) for only one possible measurement. It is not suitable for very small samples as only the carboxylic function $\mathrm{COOH}$ of the amino acids contributes to create $\mathrm{CO}_{2}$.

The best approach would be to choose the better collagen extraction method according to the bone characteristics. In most cases, both methods are applicable. As its implementation is easier, the modified Longin process could be preferred, particularly when the amount of bone is small and the sample is not too contaminated.

\section{CONCLUSION}

In this paper, preliminary results comparing two preparation methods for dating bone are presented: a modified version of the Longin method and the ninhydrin protocol have been tested on bones of different types and ages. The preservation condition of the bones was first tested by using elemental analysis and ATR-FTIR spectrometry. Elemental analysis has directly provided the $\% \mathrm{C}$ and $\% \mathrm{~N}$ contents, ATR-FTIR has quantified the collagen content and has allowed an assessment of the pre-treatment efficiency.

The modified Longin process can be used for almost all bones because the implementation is simple and requires only small sample quantities. However, some small contaminants might not be fully removed and it can be a problem for older contaminated bones. To overcome this problem, ultrafiltration or single amino acid/hydroxyproline extraction can be used. In this paper, an alter-native solution based on the ninhydrin method has been tested. In this protocol, free amino acids weakly bound to the collagen and suspected as being a contaminant should be removed efficiently by the first ninhydrin step. We have succeeded in extracting the collagen, but more contaminated bones would be necessary to confirm this point. Bones coming from museum collections or modern bones artificially contaminated with "aged" consolidant could be further investigated to assess the ninhydrin method efficiency. The main disadvantage of this method is the use of special glassware and the requirement of a large amount of sample (around $1 \mathrm{~g}$ ) for only one possible measurement. The ${ }^{14} \mathrm{C}$ results obtained with the ninhydrin method are coherent with the expected values for $2 \sigma$ uncertainty even if some results seem slightly older than those obtained with the Longin protocol.

\section{ACKNOWLEDGMENTS}

The authors gratefully acknowledge the colleagues of the LSCE for their help and particularly E. Kaltnecker for her precious advice during the laboratory experimentations. The authors thank the MNHN for providing access to the plateau de spectrométrie infrarouge. We also thank the ORAU (Oxford) for giving us the mammoth bone (Aliquot 10). Two anonymous reviewers are also thanked for their valuable remarks. The LMC14 is funded by five French organizations: CEA, CNRS, IRD, IRSN and MCC. This is LSCE contribution number 6068. 


\section{REFERENCES}

Ambrose SH. 1990. Preparation and characterization of bone and tooth collagen for isotopic analysis. Journal of Archaeological Science 17:431-51.

Beck L, Cuif J-P, Pichon L, Vaubaillon S, Dambricourt Malassé A, Abel RL. 2012. Check-ing collagen preservation in a bone fragment of the potentially Oldest Modern Indian by non-destructive studies. Nuclear Instruments and Methods in Physics Research B 273:203-7.

Bocherens H, Drucker D, Billiou D, Moussa I. 2005. A new approach for assessing the preservation state of bone and collagen for isotopic analysis (radiocarbon dating, carbon and nitrogen stable isotopes). L'anthropologie 109:557-67.

Brock F, Bronk Ramsey C, Higham TFG. 2007. Quality assurance of ultrafiltered bone dating. Radiocarbon 49(2):187-92.

Brock F, Higham T, Bronk Ramsey C. 2010. Prescreening techniques for identification of samples suitable for radiocarbon dating of poorly preserved bones. Journal of Archaeological Science 37(4):855-65.

Bronk Ramsey C, Higham T, Bowles A, Hedges R. 2004. Improvements to the pretreatment of bone at Oxford. Radiocarbon 46(1):155-63.

Brown TA, Nels on DE, Vogel JS, Southon JR. 1988. Improved collagen extraction by modified Longin method. Radiocarbon 30(2):171-7.

Dauphin Y. 2015. Messages d'os: Archéométrie du squelette animal et humain. In: Balasse M, Brugal J-P, Dauphin Y, Geigl E-M, Oberlin C, Reiche I, editors. Edition des archives contemporaines, Chapter 2p 5-21.

Debenham NC. 1998. Thermoluminescence dating of stalagmitic calcite from la grotte Scladina at Sclayn (Namur). In: Otte M, Patou-Mathis M, Bonjean D, editors. Recherches aux grottes de Sclayn Volume 2. Liège: L.Archéologie ERAUL. p 39-43.

DeNiro MJ. 1985. Post-mortem preservation and alteration of in vivo bone collagen isotope ratios in relation to palaeodietary reconstruction. Nature 317:806-9.

Dumoulin JP, Caffy I, Comby-Zerbino C, DelquéKolič E, Hain S, Massault M, Moreau C, et al. 2013. Development of a line for dissolved inorganic carbon extraction at $1 \mathrm{MC} 14$ Artemis Laboratory in Saclay, France. Radiocarbon 55(2):1043-9.

Dumoulin JP, Comby-Zerbino C, Delqué-Količ E, Moreau C, Caffy I, Hain S, Perron M, Thellier B, Setti V, Berthier B, Beck L. 2017. Status report on sample preparation protocols developed at the LMC14 Laboratory, Saclay, France: from sample collection to ${ }^{14} \mathrm{C}$ AMS measurement. Radiocarbon 59(3):713-26.

Gillespie R, Hedges REM, Wand JO. 1984. Radiocarbon dating of bones by accelerator. Journal of Archaeological Science 11:165-70.
Lebon M, Reiche I, Gallet X, Bellot-Gurlet L, Zazzo A. 2016. Rapid quantification of bone collagen content by ATR-FTIR Spectroscopy. Radiocarbon 58(1):131-45.

Leroy S, L'Héritier M, Delqué-Kolic E, Dumoulin JP, Moreau C, Dillmann P. 2015. Consolidation or initial design? Radiocarbon dating of ancient iron alloys sheds light on the reinforcements of French GothicCathedrals. Journal of Archaeo-logical Science 53(2015):190-201.

Lewis SG, Maddy D, Buckingham C, Coope GR, Field MH, Keen DH, Pike AWG, Roe DA, Scaife RG, Scott K. 2006. Pleistocene fluvial sediments, palaeontology and archaeology of the upper River Thames at Latton, Wiltshire, England. Journal of Quaternary Science Review 21(2):181-205.

Longin R. 1971. New method of collagen extraction for radiocarbon dating. Nature 230:241-2.

Marom A, McCullagh J, Higham T, Hedges R. 2013. Hydroxyproline dating: experiments on the ${ }^{14} \mathrm{C}$ analysis of contaminated and low-collagen bones. Radiocarbon 55(2-3):698-708.

Moreau C, Caffy I, Comby C, Delqué-Količ E, Dumoulin J-P, Hain S, Quiles A, Setti V, Souprayen C, Thellier B, et al. 2013. Research and development of the Artemis ${ }^{14} \mathrm{C}$ AMS facility: status report. Radiocarbon 55(2-3):331-7.

Nelson DE. 1991. A new method for carbon isotopic analysis of protein. Science 251:552-4.

Person A, Bocherens H, Mariotti A, Renard M. 1996. Diagenetic evolution and experimental heating of bone phosphate. Palaeogeography, Palaeoclimatology, Palaeoecology 126:135-50.

Scott EM, Cook GT, Naysmith P. 2010. A report on phase 2 of the Fifth International. Radiocarbon Inter-comparis on (VIRI). Radiocarbon 52(3): 84658.

Tisnérat-Laborde N, Valladas H, Kaltnecker E, Arnold M. 2003. AMS radiocarbon dating of bones at LSCE. Radiocarbon 45(3):409-19.

Ubelaker DH, Parra RC. 2011. Radiocarbon analysis of dental enamel and bone to evaluate date of birth and death: perspective from the southern hemisphere. Forensic Science International 208:103-7.

Van Klinken GJ. 1999. Bone collagen quality indicators for paleodietary and radiocarbon measurements. Journal of Archaeological Sciences 26(6):687-95.

Vogel JS, Southon JR, Nelson DE, Brown TA. 1984. Performance of catalytically condensed carbon for use in accelerator mass spectrometry. Nuclear Instruments and Methods in Physics Research B 5(2):289-93.

Wood R, Bronk Ramsey C, Higham T. 2010. Refining background corrections for radiocarbon dating of bone collagen at ORAU. Radiocarbon 52(2):60011 . 